\title{
Variety, growth and demand
}

\author{
Pier Paolo Saviotti
}

Modern economies contain a large number of entities (products, services, methods of production, competences, individual and organisational actors, institutions), which are qualitatively novel and different with respect to those existing in previous economic systems. In other words, the composition of the economic system has changed enormously during economic development. The observation that there has been a great deal of qualitative change in economic development would probably not be denied by any economist. Where, however, there would be differences is about the role of qualitative change. In order to facilitate the discussion two extreme hypotheses can be introduced: first, qualitative change is an accidental by-product of economic development; second, qualitative change is an essential component of economic development. The first hypothesis is the one implicitly present in most economic growth models, where qualitative change is not denied, but it can be accepted only ex post. The second hypothesis is central to a Schumpeterian approach, in which radical innovations change the nature of the economic system and allow the long-term continuation of economic development.

In some previous papers by this author it was argued that the concept of variety is crucial in order to overcome the gap between modelling without qualitative change and more descriptive approaches which can encompass this phenomenon (Saviotti, 1994, 1996). The most important considerations about variety contained in those papers are summarised in the following section. The main objective of this chapter, however, is the analysis of the implications of variety for demand. However, demand is seen here not on its own but as one of the components of economic development. As it will be pointed out in the section after next, one of the possible bottlenecks in economic development is constituted by the imbalance between productivity growth and demand growth within given sectors. A way to overcome such a bottleneck is represented by the emergence of new sectors, providing compensation for the displacements caused by the imbalance in existing sectors. Long-term economic development and growth then depend on the ability of the economic system to create the new goods and services leading to new sectors. 
Yet such new goods/services must be purchased by consumers if they are to contribute to economic development. The dynamics of development of demand is thus a fundamental determinant of economic development.

\section{The role of variety in economic development}

Qualitative change is here represented by variety, defined as 'the number of actors, activities and objects necessary to characterise the economic system'. Such a definition, while not being perfect, captures the essential features of qualitative change and can be the basis of quantitative and analytical treatments of economic development. The relationship between qualitative change and economic development is based on two hypotheses:

1 The growth in variety is a necessary requirement for long-term economic development.

2 Variety growth, leading to new sectors, and productivity growth in existing sectors, are complementary and not independent aspects of economic development.

These have to be considered very strong working hypotheses, having a considerable empirical and theoretical support, but not yet definitively proved. Furthermore, these hypotheses can be valid in the long run and at sufficiently high levels of aggregation, for example that of a national economy.

The justification for these hypotheses comes mainly from Pasinetti's work (1981, 1993). The bottleneck created by the imbalance between demand saturation and continuous productivity growth in existing sectors can be compensated for by the emergence of new sectors. On the other hand, the resources required to perform search activities and thus to create new sectors can come only from productivity improvements in existing sectors. In this sense the complementarity between variety growth and productivity growth in existing sectors bears a considerable similarity to that between productivity growth in agriculture and investment in the new industries during the process of industrialisation (see Kuznets, 1965; Landes, 1998). Further support for the role of variety in economic development comes from Romer's models $(1987,1990)$ that include a growth in the number of capital goods among the consequences of innovation.

\section{Variety and demand}

If the overall variety of the economic system has to increase in the course of time then not only have entrepreneurs and producers to create new goods/services but consumers and user must buy them. The net variety of the economic system, that is, the variety that survives the process of selection, is constituted by the goods/services that are produced and consumed. Furthermore, as it will be seen later, goods/services created by an innovation go through a life cycle during which they are improved and can appeal to a 
growth market. Thus, demand is involved in an essential way in the longterm growth of variety.

\section{The consumer as an innovator}

The qualitative change taking place in economic development creates new goods/services. Consumers have available a much wider range of these than was the case in previous economies. The demand theory that is normally presented in textbooks can deduce the behaviour that follows from a given set of preferences. Preference formation is not considered a legitimate subject of analysis for economics, but it is left to other disciplines in the social sciences. Such an approach would be perfectly adequate if consumers did not change. However, if we are concerned with long-term economic development the assumption of static consumers is inadequate. As Georgescu-Roegen (1954) remarked a long time ago, 'man is a continuously changing structure'. Unless we assume that they were already present in humankind before objects of consumption came into existence, wants and preferences have to be formed during the process of economic development.

The problem of wants and preference formation becomes particularly urgent, if, as Schumpeter tells us, radical innovations are essential to the long-term continuation of economic development. In fact we can argue that the more radical an innovation is, the less predictable its properties and uses are. Neither consumers and users on the one hand, nor producers on the other, can always estimate what goods/services will be demanded. Perhaps the most spectacular example of failure to estimate demand occurred in the case of mainframe computers, the total demand for which in both the United States and the United Kingdom was assessed at four or five machines, to be greatly outperformed by real demand. This was not just a failure by producers or marketing experts to estimate a demand which was clearly there, but a case in which the demand itself was not formed because the potential users did not know about the properties of the object they were later to demand. In general, we can assume that the mental categories required to understand the properties of a good or service and the ways in which it can be used are not there before the good or service is created. Therefore, wants and preferences will be created gradually during the life cycle of a good or service, and the mechanisms of their formation are a problem at least as interesting as the behaviour that can be deduced from them, if we are interested in long-term economic development. (On this point see also Teubal, 1979; Teubal et al., 1991, 1994.)

Aversi et al. (1999) summarise the considerable evidence that preferences are constructed through the very process of deliberation (p. 362) and that their construction corresponds to a satisficing inferential machinery (p. 362). Moreover, habits and routines coexist with deliberative decision processes (p. 363). In general we can say that demand theory may require a number of modifications if our main emphasis is on long-term behaviour. We can 
imagine preferences to be an internal ranking order based on the individual's past consumption activity. The process of choice can then be described as the encounter of an object of consumption followed by the comparison of the object with the internal ranking order and by the decision whether to purchase and what level of resources to allocate. In this context an object of consumption can be a good or a service and the encounter with it consists of information about the object and its properties. The theory of demand usually found in economics textbooks amounts to considering that the internal ranking order is given ex ante and that it is sufficiently accurate to allow an unambiguous allocation of resources to different objects of consumption. Such a perspective may be entirely adequate if the choice is to be made among a set of objects of consumption which are known and for which individuals have a definite ranking order. The same perspective becomes insufficient if the problem to be analysed is long-term economic development, in the course of which entirely new and unpredictable new objects of consumption emerge.

Thus the consumer cannot be considered constant and invariant with respect to economic development. On the contrary, we need to consider the consumer as an innovator (Earl, 1986), although the meaning of the word will be somewhat different here with respect to that customarily used in innovation studies. The consumer is an innovator when he/she encounters a new object of consumption of which he/she has only incomplete or no knowledge. The process of consumption has to be preceded by a period of learning about the properties of the new object. At the beginning of the life cycle of a completely new product a consumer cannot easily understand its properties and the contribution that it can make to his/her utility. The process of learning is gradual, and at the beginning it is generally stimulated by the initiative of the producers and by the example of other consumers. Adopting a terminology used in innovation studies, the consumer needs to acquire an absorption capacity (Cohen and Levinthal, 1989, 1990) for the new object.

Consumers endowed with an absorption capacity are able to evaluate the properties of the new object and its contribution to their utility. Alternatively, we can say that the consumer must have a knowledge base sufficiently developed in the fields underlying the new object. For example, the use of computers requires a minimum level of knowledge in information technology and the use of photographic cameras knowledge of the principles of photography. Of course, this means that the human capital of consumers must continuously increase in order to be able to incorporate the knowledge base required for the consumption of the new objects. The new preferences created through this process of learning are not immediately accurate, but they are fuzzy. That is, if the same consumer were to be faced with the choice of the same object twice he/she would not necessarily repeat the same choice. In other words, the greater the degree of novelty of the new object of consumption, the greater the uncertainty involved in its choice. One way in which this uncertainty can be reduced 
is by observing the behaviour of other consumers and by imitating them. Imitative behaviour has two consequences: it reduces the uncertainty involved in the choice and it enhances the convergence among the choices of different consumers. We can then expect the internal ranking order of different consumers to become more accurate as a consequence of imitative behaviour. The ranking orders of different consumers will thus be interdependent, particularly if consumers share the same culture (Georgescu-Roegen, 1954, p. 517).

The interdependence of the preferences and of the utility functions of different consumers does not imply complete convergence of their preferences and wants. One of the most common trends observed in consumption is the growing differentiation, or even individualisation, of consumers' choices as their income grows. Thus we have to acknowledge that as new objects of consumption are created there are forces leading both to the convergence and to the divergence of individual ranking orders.

The previous considerations imply that the creation of a radical innovation cannot be stimulated by existing demand. If preferences cannot pre-exist objects of consumption, consumers cannot have a demand for goods or services that do not exist and of which in some cases they do not even imagine the existence. It is then the role of producers to imagine some potential demand and to create an innovation that can satisfy it. Since consumers may not have the ability to evaluate the new innovation, it is also the role of producers to 'educate' them, that is, to supply consumers with enough knowledge for them to be able to evaluate the new object of consumption. Yet producers themselves do not have a very sophisticated knowledge of the user environment of the innovation. They themselves are learning in the process of producing and subsequently modifying the new object of consumption. In other words, during the life cycle of a good or service a gradual process of learning takes place both on the producer's and on the consumer's side. During this process demand as we know it is created. Producers learn how to produce goods or services better adapted to consumer requirements and consumers improve their ability to use the new good or service. In general we can then expect the initiative for the creation of a radical innovation to be taken by producers and demand to become progressively more important as the innovation matures. Schumpeter was then right in predicting that producers would have to 'educate' consumers to use new goods/services, but the role of demand becomes gradually more important as the goods/services mature, thus confirming Schmookler's ideas about innovation. This pattern of a gradual shift of importance away from the supply side and towards the demand side was confirmed by Walsh (1984) for the synthetic materials industry.

\section{A hierarchical theory of wants and preferences}

A hierarchical theory of wants has been discussed by several among the leading neoclassical economists, such as Walras (1896), Jevons (1924), Marshall (1949), but it has received its most explicit and detailed treatment in the 
work of Menger (1950). Such theory implies that wants can be ranked in order of absolute importance, with the most basic wants at the bottom of the list (lower wants) and with the most sophisticated (higher wants) at the top. For example, the uses of corn for an isolated farmer can be ranked in order of importance (Menger, 1950, p. 129): food, seed for next season, alcoholic beverages, fodder, rearing parrots. Of course, we expect that the list of wants of the average individual will grow longer as his/her income rises during economic development. In this sense we can imagine preferences to be a preestablished ranking order that consumers apply to any choice they make. For example, when they have to choose between two goods they compare the goods with the ranking order and allocate to them a corresponding share of their income. A problem arises when a new good is encountered. Then the ranking order has to be modified to include the new good. The problem would be relatively simple if all new goods/services corresponded to higher wants, that is, if they had to be added 'on top' of the existing ones. However, we cannot expect the actual ranking order of goods/services to be the same for all individuals. Like other types of economic agents, consumers are heterogeneous. Furthermore, we can expect that as income per head rises individual consumption will become more and more differentiated, giving rise to a diversity of consumer's choices, thus increasing their heterogeneity.

Even though this diversity will be limited by imitation, and even though the wants of individuals will tend to converge more if they live within the same culture than in different ones (Georgescu-Roegen, 1954, p. 517), we cannot assume that at higher levels of economic development the order of wants will be the same for all individuals. Second, if mechanisms of demand formation show increasing returns to adoption, demand development is likely to show path dependence (Arthur, 1989). Thus an initial choice of some wants, however 'rational', may lead to a non- uniform demand development path. Moreover, another form of path dependence may be induced by past patterns of consumption. If the goods/services that were consumed in the past increase differentially the probability of consumption of some present goods, then a form of path dependence which originated in the past can be extended to the future (David, 1985). In summary, and remembering that these are preliminary considerations, we can point to the non-uniformity of the ranking order of wants at high levels of economic development. A number of other implications for demand theory follow from the hypotheses on growing variety.

A hierarchical theory of wants and preferences can be translated into an analytical treatment by means of the concept of critical income. Critical income is defined (Bonus, 1973) as the minimum income level that a consumer would need to purchase a given good. There will be a critical income associated with each type of differentiated good or service and the value of the critical income can be expected to increase as we move away from basic goods or services and towards higher levels on the hierarchical scale. Thus international travel, photography or theatre are likely to correspond to 
higher values of critical income than housing or food. However, we can also expect that while everyone consumes food not everyone will rank theatre or photography equally high, even at equivalent income per head. As income per head grows we can expect the hierarchical scale to become progressively more uncertain: the ranking order of different consumers will differ more the higher the hierarchical level. In other words, the higher the level of the want, the higher the uncertainty attached to it, this uncertainty being a measure of consumer heterogeneity.

Other types of barriers to consumption exist in addition to critical income. As will be pointed out later, consumers need to have a minimum level of knowledge and hence of human capital in order to understand the properties of a new object of consumption. Furthermore, the new good or service needs to have a minimum level of efficiency in order to attract consumers. In this chapter efficiency will be represented by fitness, that is, by the ability of the good or service to adapt to its intended user environment. Consumers will then need to have at least the critical value of human capital, and the new object of consumption will need to have at least the critical value of fitness. Here it must be pointed out that the fitness of a particular good or service varies in different parts of characteristics space. If we take a good supplying particular services, measure the corresponding service characteristics (Saviotti and Metcalfe, 1984), the fitness of such goods can be very high in a small sub-set of characteristics space while being lower than average fitness everywhere else. For example, large jet aircraft will be the most suitable means of transport over distances of at least several hundred kilometres. For shorter distances, trains or buses constitute fitter means of transport. Likewise, the size of the sub-set of characteristics space in which a new good or service has a high fitness can increase in the course of time. At the beginning of their life cycle many new goods and services occupy a niche in which their fitness is sufficiently high to interest a small population of users/consumers. In the course of the life cycle of the good or service its properties improve and its price falls, thus increasing the size of the population of consumers that can use it. In other words, starting from the very small niche in which it begins, an innovation, by means of subsequent improvements, can appeal to a much larger population of consumers/users. (For a similar treatment of innovation diffusion see Metcalfe, 1988.) In this process what was initially a niche becomes a market.

\section{Convergence and divergence in consumer choice}

As previously pointed out, in general we can observe increasing differentiation in the outputs of the economy. The choice behaviour of consumers needs to become increasingly differentiated in order to support these trends. However, such increasing differentiation is the result of the balance between forces leading to convergence and to divergence in consumers' tastes and preferences. The nature of these forces will now be discussed. 
Consumers' wants can be placed in a hierarchical order, with more basic wants occupying lower levels and more 'sophisticated' wants occupying gradually higher levels. It was also pointed out that the presence of basic wants was virtually universal, while the presence of higher wants is likely to show greater variation among consumers. Thus everyone needs some food while not everyone needs to be a classical music lover. We can then say that the degree of convergence among consumers' choices is likely to be greater for 'low' than for high levels of consumption. It must be pointed out that even for a low-level category of consumption, such as food, internal differentiation of the category can take place: although everyone consumes food, the kind of food consumed is becoming increasingly differentiated. Thus we need to distinguish between convergence of categories and convergence within categories of consumption.

What then are the forces leading to convergence of consumer choice? At low hierarchical levels strong physical constraints determine consumer behaviour. No one can remain without food or shelter. However, if consumer choices were purely individual these strong structural determinants of consumer behaviour would become gradually less important as we move up the hierarchical ladder. This corresponds to the observed increase of differentiation of consumer choice for higher hierarchical levels. Does this mean that at higher hierarchical levels the interdependence of consumers falls and that utility functions become purely individual? Hirsch's (1976) observation that in high-income societies poverty is relative gives us a clue here. Only if consumers observe other consumers' behaviour can poverty become relative. A consumer who has not yet adopted will then observe those who have already become adopters of a new good or service and try to imitate them. Imitative behaviour then becomes a powerful force leading to convergence in consumption. In fact not all consumers need to replicate the choices of those who have already become adopters. According to Cowan et al. (1997) consumers can attempt to imitate some groups and differentiate themselves sharply from others. Thus convergence is not necessarily general, but limited to particular social groups. In this sense imitation can be a force leading to both convergence and divergence: by imitating certain consumers one joins them and constitutes with them a group, but different groups are created when consumers differentiate themselves from others.

Another force leading to convergence is scale economies. A trade-off has to be reached between increasing variety and scale economies (Lancaster, 1975). However, the effect of scale economies is likely to fall both as we move towards higher income per head and as a result of the increasing flexibility of production methods.

We conclude the analysis of the forces leading to convergence by pointing out that although structural determinants leading to convergence are likely to be stronger at low hierarchical levels of consumption they are by no means absent at higher hierarchical levels. For example, purchases of cars or household appliances are not uniquely the result of individual choice but have to 
do with the increasing distance travelled to work, a result of urban geography or of the increasing frequency of households where all adults work. Thus the forces leading to convergence of consumer choices will be a combination of structural constraints, scale economies and imitative behaviour.

Amongst the forces leading to divergence, the saturation of consumption is probably the most fundamental. Not only does marginal utility fall with increasing consumption, it can even become negative. Thus total utility would increase more by beginning to consume a new good or service than by increasing the quantity consumed of an existing one. Thus if consumers maximise their utility subject to constraints they are likely to differentiate their consumption gradually as their income per head grows. This increasing differentiation determined by the saturation of demand corresponds to a natural differentiation existing amongst consumers. In fact the limited differentiation in consumer choices that existed in the past could be attributed to the high costs of producing such very limited amounts of differentiation.

\section{A population approach}

In this chapter demand will be represented by means of a population of consumers. A particular consumer population will be created as a new object of consumption becomes available and as the first consumer starts purchasing it. After the population has been created it will have a dynamic, constituted by the entry of new consumers and by the exit of some existing consumers. As was previously pointed out, entry into a population of consumers will take place only after certain barriers have been overcome: the consumer needs to have income and human capital at least equal to the critical values required, and the new good or service needs to have reached a minimum level of efficiency or fitness. Once these barriers have been overcome entry will be determined by the excess of income, human capital and fitness with respect to their critical values and by the example of other consumers. However high the level of human capital of the consumer, it can never remove completely the uncertainty involved in the new good or service. Imitative behaviour considerably reduces the impact of uncertainty on decision making.

Exit from a consumer population occurs when a consumer stops purchasing the corresponding good or service. The most likely cause of that is the emergence of a newer good or service that has more attractive properties for the consumer. Of course, exit here means both the complete exit of a consumer or a reduction in the fraction of income that he/she allocates to the particular good or service. The dynamics of this population is described in a more analytical way in Saviotti (2000), to which the interested reader is referred.

Demand is seen here as a part of the process of economic development. A population of consumers is created when a new object of consumption is available and the first consumer starts purchasing it. Here we must take into account explicitly three populations: (1) the population of the new good or service, constituted by the distribution of the differentiated product models in 
characteristics space; (2) the population of firms producing such product models; (3) the population of consumers consuming these product models. Of course, these three populations are interacting. The dynamics of demand then interacts with that of the creation of new goods and services. The innovation constituted by a new good or service is introduced owing to a combination of the saturation of existing populations and to a number of positive inducements to the creation of a new population.

As pointed out by Andersen (1999), when using railways as a prototype of the introduction of a wide-ranging innovation, Schumpeter maintained that such innovation at the beginning of its life cycle would exert powerful inducements on entrepreneurs to enter its production, but it would eventually lose this initial momentum and be transformed into a routine of the economic system. In this chapter, two types of factors slow down and in the end completely eliminate the inducement for producers to enter a given population. First, as more and more firms imitate the initial entrepreneur(s) who created the new population, the intensity of competition increases. If we remember that the expectation of a temporary monopoly was a very important inducement for entrepreneurs to create an innovation (Schumpeter, 1934), we will realise that the gradual erosion of this temporary monopoly, leading the sector created by the innovation to become a more routine part of the economic system, reduces the inducements for imitators to enter and may induce incumbent firms to exit. Of course, the increasing intensity of competition is likely to reduce profit margins to the levels that are enjoyed in the routine sectors of the economy. Second, a similar effect is created by the gradual saturation of demand. When all possible consumers have purchased one unit of the new good or service, sales do not become merely repeat sales, owing to the possibility of qualitative improvements of the good or service itself, so further inducements to enter can be expected to disappear and inducements to emerge for incumbents to exit. Thus the combination of increasing intensity of competition and of the saturation of demand gradually slows down the rate of entry and may even lead to a net rate of exit during certain phases of the life cycle of a good or service.

In order to lead to growing overall variety in the production system innovations need to create new populations of goods and services together with the related populations of producers and of consumers. Negative inducements to enter existing populations need to be coupled with positive inducements to create niches in which innovations can begin their diffusion process. Whether such a niche subsequently becomes a market and what size the market will be depend on the range of performance of the new good or service and on its rate of improvement. Rapidly falling costs and prices and improving performance will substantially widen the population of consumers that can purchase the good or service and hence its market.

The process of creation of new populations of good and services interacts with that of creation of their producers and consumers. In particular, as far as the present discussion is concerned, the population of a new good or service 
would never emerge and develop unless a population of consumers was ready to purchase it. The size and properties of the two populations are likely to change interactively in the course of time. If the properties of the new good or service improve and its price falls more consumers are going to purchase it. On the other hand the rate of increase of demand is likely to exert a powerful influence on the investment and entry decisions of producers.

In summary, in this chapter we have emphasised the dynamics of a population of consumers. Such dynamics interact with that of the population of the new good or service and of its producers. The interaction can be represented in the form of a life cycle in which an innovation after creating a niche gradually evolves into a market, thus becoming an additional routine element of the economic system.

\section{On the conditions for variety growth}

In order for the overall variety of the system to increase at least a part of the new goods/services created by innovators must survive together with the preexisting goods/services. Alternatively, not all the new goods/services must be functional substitutes for existing goods/services. The conditions for variety growth are then the conditions for the coexistence of new and existing goods/services. This problem demands an analytical solution, which is beyond the scope of this chapter. Such an analytical solution is provided in Saviotti (2000). In what follows we give a qualitative representation of it.

We can concentrate on two populations of goods/services, an old one (Old) and a new one (New). First, we can apply to these populations a general result that can be obtained by means of the so-called Lotka-Volterra equation (Saviotti, 2000; Saviotti and Mani, 1995). Coexistence will be possible if the intensity of competition within each of the two populations (intra-group competition) is higher than the intensity of competition between them (intergroup competition). Such a general result is applicable to any type of population constituted by potentially competing 'species'. It is, however, possible to translate this result into a form related to the specific nature of the populations of goods/services that we are considering. We can expect the decision of a consumer to add a new good/service to those that he/she is already consuming or to substitute an old good/service with a new one to be determined by the relative fitness of Old and of New. Yet we can demonstrate analytically that even if New has a higher fitness than Old, consumers will not necessarily discard Old for New. Two variables determine whether, when New is superior to Old, consumers adopt New and discard Old (exclusion) or whether, while adopting New, they continue to buy Old (coexistence). The two variables represent the extent of differentiation of New with respect to Old and the knowledge that consumers have of New. The more differentiated New is with respect to Old, the less likely that they are going to be substitutes. Consumers would discard Old in favour of New if they were perfect substitutes, but could purchase both of them if they were different. Second, even if 
New were a very close and superior substitute for Old, if consumers did not understand fully the properties of New they could, at least for a while, keep purchasing Old while adopting New.

These results can be summarised in the following way. Variety growth requires the coexistence of New and Old. Such coexistence can take place if two conditions are satisfied:

1 Old and new are not substitutable but are different goods/services.

2 Consumers have a limited knowledge of the properties of New and cannot decide whether to purchase it.

Thus differentiation of new goods/services with respect to existing ones and a degree of ignorance about the properties of new goods/services are important factors contributing to the growth in the overall variety of the economic system. According to hypothesis 1 we can conclude that long-term economic development will be better served by differentiation and by a degree of consumer ignorance about the properties of an emerging good/service than by superior substitutes for old goods/services of which consumers know accurately all the properties.

The more general result stating that intra-group competition must be greater than inter-group competition if variety is to grow has interesting implications. It is customarily assumed that a more competitive economy is likely to be more efficient. Yet this result tells us that the best conditions for economic development do not coincide with the maximum possible intensity of competition. In fact, prospects for long-term economic development are better if inter-group competition is less intense than intra-group competition. This condition can be interpreted as a relative 'blindness' of the incumbent firms producing Old to the competitive threat posed by New. This relative blindness reduces the barriers to the introduction of New in the early phases of its life cycle and facilitates the emergence of New as a stable economic species. Alternatively, the greater the differentiation of New with respect to Old the smaller the competitive threat that it will pose. We can then see that the dynamics of demand in the long run is intimately linked with the competition between new and old goods/services.

\section{Summary and conclusions}

The main objective of this chapter was to discuss the role of demand in variety growth and thus in long-term economic development. Variety grows owing to the introduction of new goods/services qualitatively different from those that preceded them. These new goods/services can contribute to variety growth if they are produced and consumed. A dynamic theory of demand compatible with the analysis of long-term economic development needs to take into account the formation of preferences and wants corresponding to the new goods/services. In this chapter the dynamics of demand is analysed by a combination of a hierarchical theory of demand and of a population 
approach. Wants can be classified in a hierarchical order, with the most basic ones corresponding to lower levels and the more sophisticated ones to higher levels. In order to start purchasing a new good/service and thus to create a new population, consumers must overcome a number of barriers: they must have at least the critical income and the critical human capital corresponding to the new good/service, and the good/service itself must have at least the critical fitness.

The analytical treatment of the dynamics of consumer populations leads to the conclusion that variety is likely to grow if the new good/service is not a substitute for old ones but is different from them, and if consumers' knowledge of the properties of the new good/service is so limited as not to allow them to evaluate its contribution to their utility. Alternatively, variety can grow if the intensity of competition within each population of goods/services is higher than the intensity of competition between different populations.

We can then conclude that the analysis of demand is inseparable from that of economic development and that economic development itself proceeds more by creating a wider range of distinguishable types of goods/services whose properties are only imperfectly known by consumers at the beginning of their life cycle than by creating superior substitutes for existing goods/services about which consumers have perfect knowledge.

\section{Acknowledgement}

The considerations in the section entitled 'The role of variety in economic development' are a summary of previous papers (Saviotti, 1994, 1996).

\section{References}

Andersen, E. S. (1999), 'Railroadization as Schumpeter's Standard Example of Capitalist Evolution: an evolutionary-ecological interpretation', paper presented at the workshop on the History of Evolutionary Thought in Economics, Max Planck Institute of Economic Research, Evolutionary Economics Unit, Jena, 26-8 August.

Arthur, W. B. (1989), 'Competing technologies, increasing returns, and lock-in by historical events', Economic Journal, 99, pp. 116-31.

Arthur, W. B. (1994), Increasing Returns and Path Dependence in the Economy, Ann Arbor MI, University of Michigan Press.

Aversi, R., Dosi, G., Fagiolo, G., Meacci, M., and Olivetti, C. (1999), 'Demand dynamics with socially evolving preferences', Industrial and Corporate Change, 8 , pp. 353-99.

Bonus, H. (1973), 'Quasi-Engel curves, diffusion and the ownership of major consumer durables', Journal of Political Economy, 81 (3), pp. 655-77.

Cohen, M., and Levinthal, D. (1989), 'Innovation and learning: the two faces of R\&D', Economic Journal, 99, pp. 569-96.

Cohen, M., and Levinthal, D. (1990), 'Absorptive capacity: a new perspective on learning and innovation', Administrative Science Quarterly, 35, pp. 128-52. 
Cowan, R., Cowan, W., and Swann, P. (1997), 'A model of demand with interactions among consumers', International Journal of Industrial Organization, 15, pp. 711-32.

David, P. A. (1975), Technical Choice, Innovation and Economic Growth, Cambridge, Cambridge University Press.

David, P. A. (1985), 'Clio and the economics of QWERTY', American Economic Review Proceedings, 75, pp. 332-7.

Earl, P. (1986), Lifestyle Economics: consumer behaviour in a turbulent world, Brighton, Wheatsheaf Harvester.

Georgescu-Roegen, N. (1954), 'Choice, expectations and measurability', Quarterly Journal of Economics, 68, pp. 503-34.

Hirsch, F. (1976), Social Limits to Growth, New York, Harvard University Press.

Jevons, W. S. (1924), The Theory of Political Economy, fourth edition, London, Macmillan.

Kuznets, S. (1965), Economic Growth and Structure, New York, Norton.

Lancaster, K. J. (1975), 'Socially optimal product differentiation', American Economic Review, 65 (4), pp. 567-85.

Landes, D. (1998), The Wealth and Poverty of Nations, London, Little Brown.

Marshall, A. (1949), Principles of Economics, eighth edition, London, Macmillan.

Menger, C. (1950), Principles of Economics, New York and London, New York University Press.

Metcalfe, J. S. (1988), 'The diffusion of innovation', in Dosi, G., Freeman, C., Nelson, R., Soete, L., and Silverberg, G. (eds), Technical Change and Economic Theory, London, Pinter.

Pasinetti, L. L. (1981), Structural Change and Economic Growth, Cambridge, Cambridge University Press.

Pasinetti, L. L. (1993), Structural Economic Dynamics, Cambridge, Cambridge University Press.

Romer, P. M. (1987), 'Growth based on increasing returns due to specialization', American Economic Review, 77, pp. 56-62.

Romer, P. M. (1990), 'Endogenous technological change', Journal of Political Economy, 98 (5), pp. S71-102.

Saviotti, P. P. (1994), 'Variety, economic and technological development', in Shionoya, Y., and Perlman, M. (eds), Technology, Industries and Institutions: studies in Schumpeterian perspectives, Ann Arbor MI, University of Michigan Press.

Saviotti, P. P. (1996), Technological Evolution, Variety and the Economy, Aldershot, Elgar.

Saviotti, P. P. (2001), 'Variety, growth and demand', Journal of Evolutionary Economics, 11 (1), pp. 119-42.

Saviotti, P. P., and Mani, G. S. (1995), 'Competition, variety and technological evolution: a replicator dynamics model', Journal of Evolutionary Economics, 5 (4), pp. 369-92.

Saviotti, P. P., and Metcalfe, J. S. (1984), 'A theoretical approach to the construction of technological output indicators', Research Policy, 13, pp. 141-51.

Schumpeter, J. (1934) [1912], The Theory of Economic Development, Cambridge MA, Harvard University Press.

Teubal, M. (1979), 'On user needs and need determination', in Baker, M. (ed.), Industrial Innovation, London, Macmillan.

Teubal, M., and Zuscovitch, E. (1994), 'Knowledge differentiation and demand 
revealing through network evolution', in Karlsson, C., Johansson, B., and Westin, L. (eds), Patterns in a Network Economy, Heidelberg, Springer.

Teubal, M., Yinnon, T., and Zuscovitch, E. (1991), 'Networks and market creation', Research Policy, 20, pp. 381-92.

Walras, L. (1896), Eléments d'économie politique pure, third edition, Lausanne, Rouge.

Walsh, V. (1984), 'Invention and innovation in the chemical industry: demand pull or discovery push?' Research Policy, 13, pp. 211-34. 